\title{
Foregut function before and after lung transplant
}

Takahiro Masuda, MD, ${ }^{\mathrm{a}, \mathrm{b}}$ Sumeet K. Mittal, MD, ${ }^{\mathrm{a}, \mathrm{b}}$ Balázs Kovács, MD, ${ }^{\mathrm{a}}$ Michael A. Smith, MD, Rajat Walia, MD, ${ }^{\mathrm{a}, \mathrm{b}}$ Jasmine L. Huang, MD, ${ }^{\mathrm{a}, \mathrm{b}}$ and Ross M. Bremner, MD, PhD ${ }^{\mathrm{a}, \mathrm{b}}$

\section{ABSTRACT}

Background: Esophageal dysmotility and gastroesophageal reflux disease are common in patients with advanced lung disease and can potentially affect outcomes of lung transplant; however, the effects of lung transplant on foregut function remain unknown. We assessed foregut function before and after bilateral lung transplant.

Methods: We attempted complete foregut function testing before and after lung transplant. We compared patients with obstructive lung disease and patients with restrictive lung disease who underwent lung transplant between 2015 and 2016.

Results: In total, 112 patients met inclusion criteria. The mean age of patients was 62.2 years, and 62 patients were men. A total of 51 patients $(45.5 \%)$ were diagnosed with obstructive lung disease, and 56 patients $(50.0 \%)$ were diagnosed with restrictive lung disease. Approximately half of these patients had a change in manometric diagnosis before and after lung transplant, with most achieving increased peristaltic vigor. Pre-lung transplant gastroesophageal reflux disease was more prevalent in the restrictive lung disease cohort than in the obstructive lung disease cohort $(42.9 \%$ vs $19.6 \%, P=.010)$. Thoracoabdominal pressure gradient before lung transplantation was greater in the restrictive lung disease group than in the obstructive lung disease group (23.4 vs $14.7 \mathrm{~mm} \mathrm{Hg}$, $P<.001$ ), which may explain the mechanism of increased reflux in patients with restrictive lung disease. No differences were seen in the post-lung transplant prevalence of pathological reflux and thoracoabdominal pressure gradient between groups.

Conclusions: Esophageal motility and reflux parameters vary significantly between patients with obstructive lung disease and patients with restrictive lung disease, and can be explained by differences in underlying pulmonary dynamics. Restoring pulmonary physiology after lung transplant ameliorates the effects of esophageal dysmotility and reflux. Improved peristaltic vigor after lung transplant in patients with hypomotility is important, which may make them eligible for antireflux surgery if gastroesophageal reflux disease persists after lung transplant. (J Thorac Cardiovasc Surg 2019;158:619-29)

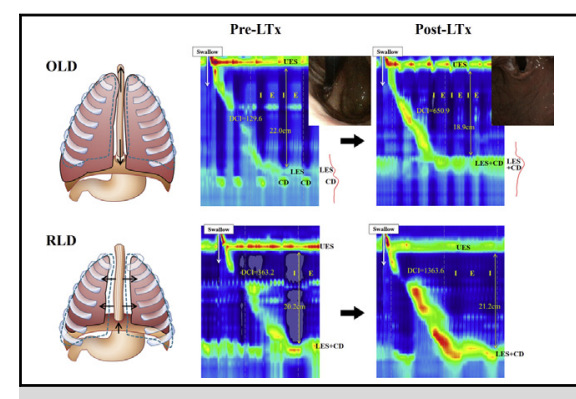

Poor esophageal motility before LTX has improved after transplantation.

\section{Central Message}

Esophageal motility and reflux parameters vary drastically between patients with obstructive lung disease and patients with restrictive lung disease. These differences are ameliorated after LTx.

\section{Perspective}

Advanced lung disease dramatically changes lung volume and results in a dynamic shift of force upon the esophageal wall, a phenomenon that can impair esophageal motility. Derangement of thoracoabdominal pressure gradient affects the prevalence of pathological reflux between obstructive and restrictive lung disease before LTx. These differences are diminished after LTx.

See Commentary on page 630 .

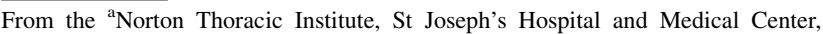
Phoenix, Ariz; and ${ }^{\mathrm{b}}$ Creighton University School of Medicine-Phoenix Regional Campus, Phoenix, Ariz.

Institutional Review Board Number: PHXA-17-0172-71-18. Institutional Review Board Approval Date: July 6, 2017.

Read at the 43rd Annual Meeting of The Western Thoracic Surgical Association, Colorado Springs, Colorado, June 21-24, 2017.

Received for publication Aug 24, 2018; revisions received Jan 31, 2019; accepted for publication Feb 24, 2019; available ahead of print May 11, 2019

Address for reprints: Sumeet K. Mittal, MD, Norton Thoracic Institute, St Joseph's Hospital and Medical Center, 500 W Thomas Rd, Ste 500, Phoenix, AZ 85013 (E-mail: Sumeet.Mittal@DignityHealth.org).

$0022-5223 / \$ 36.00$

Copyright (C) 2019 by The American Association for Thoracic Surgery https://doi.org/10.1016/j.jtcvs.2019.02.128
}

Gastroesophageal reflux disease (GERD) is common in patients with advanced lung disease, and GERD prevalence may remain high after lung transplant (LTX). ${ }^{1-4}$ Growing clinical and experimental evidence demonstrates that GERD is associated with pulmonary allograft dysfunction, known as "bronchiolitis obliterans syndrome," and is linked to chronic aspiration. ${ }^{5-8}$ Poor

$\square$ Scanning this QR code will
take you to the article title
page to access supplementary
information.




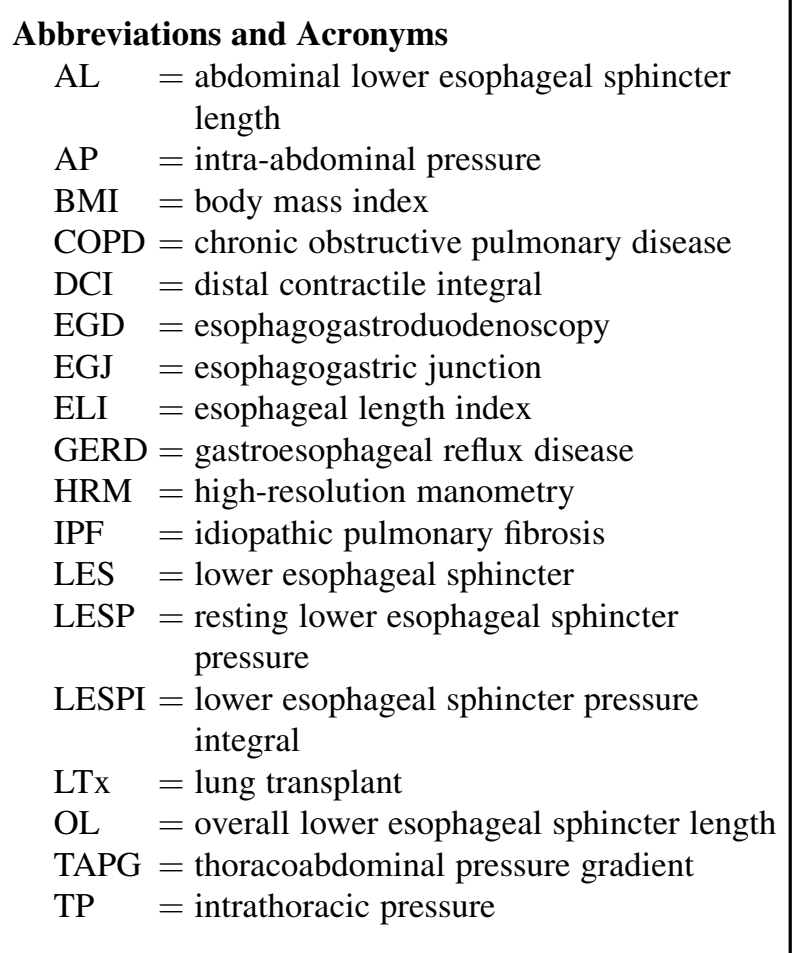

esophageal bolus transit, elevated thoracoabdominal pressure gradient (TAPG), ineffective lower esophageal sphincter (LES) antireflux function, and delayed gastric emptying increase the risk of retrograde flow of gastric contents into the esophagus. A recent animal study reported that when bronchiolitis obliterans syndrome is induced by repeated aspiration, it cannot be prevented by gastric acid neutralization therapy. ${ }^{9}$ This suggests that antireflux surgery may have an important role in preserving long-term allograft function after LTx. We have reported that early fundoplication after transplant has a protective effect on lung function in patients diagnosed with GERD. ${ }^{10}$ Therefore, a detailed understanding of foregut function in LTx recipients is required for improved clinical strategy.

Obstructive lung disease and restrictive lung disease are known to have contrasting respiratory mechanics. Significant differences in the types of esophageal disorders and the prevalence of pathological reflux in patients with obstructive and restrictive lung disease before LTx have been reported. ${ }^{11,12}$ However, differences in foregut function before and after LTx remain unknown, especially in terms of each specific pulmonary disease. The aim of this study is to evaluate the effect of LTx on foregut function based on underlying lung disease type.

\section{MATERIALS AND METHODS}

All patients who undergo LTx at our institution are entered into a prospectively maintained database at Norton Thoracic Institute in Phoenix,
Arizona. We obtain complete foregut function testing, which includes high-resolution manometry (HRM), 24-hour $\mathrm{pH}$ testing, endoscopy, and gastric emptying studies for all patients whenever clinically possible. After Institutional Review Board approval (\#PHXA-17-0172-71-18), we queried that database to identify patients who underwent LTx between January 2015 and December 2016. Of these patients, those who underwent both pre- and post-transplant HRM with a 24-hour pH study were selected. We excluded patients who had undergone previous LTx, foregut surgery, or endoscopic intervention for the esophagogastric junction (EGJ), such as pneumatic balloon dilation. Patients were also excluded if their HRM study was unavailable for reanalysis or of poor quality, if they underwent $\mathrm{pH}$ monitoring while taking acid-suppression medications (ie, proton pump inhibitors within 7 days or $\mathrm{H} 2$ receptor antagonists within 3 days before 24-hour $\mathrm{pH}$ study), or if they had a poor-quality $\mathrm{pH}$ study. Patients' underlying pulmonary disease was classified using United Network for Organ Sharing criteria. Patients were classified into 1 of 4 groups: obstructive lung disease (United Network for Organ Sharing criteria Group A), pulmonary hypertension (Group B), cystic fibrosis (Group C), or restrictive lung disease (Group D).

\section{High-Resolution Manometry}

Pre- and post-LTx HRM were performed with a 36-channel catheter with circumferential solid-state pressure transducers placed at $1-\mathrm{cm}$ intervals (Given Imaging, Yokne'am Illit, Israel). Most investigations were conducted within 6 months before and 6 months after LTx. All studies were reanalyzed using Manoview software version 3.0.1 (Given Imaging) by a single author (TM). The pressure topography of ten $5-\mathrm{mL}$ water swallows was assessed using Chicago classification v3.0. ${ }^{13}$ Studies were considered to be of poor quality if the catheter was positioned inappropriately; if there was an inadequate baseline recording for LES and gastric pressure; or if swallows were unsuitable for accurate analysis due to coughing, belching, or other factors. Esophageal body peristaltic vigor was calculated by the average of the distal contractile integral (DCI) in 10 water swallows. EGJ barrier function against gastroesophageal reflux was also assessed using previously established manometric parameters: overall LES length (OL), intra-abdominal LES length (AL), resting LES pressure (LESP), ${ }^{14}$ and LESP integral (LESPI). ${ }^{15}$

Intra-abdominal pressure (AP), intrathoracic pressure (TP), TAPG, and adjusted TAPG were measured during a resting period without swallowing or esophageal peristalsis (Figure 1), according to previously described methods. ${ }^{16}$ Briefly, AP was defined as the pressure $1 \mathrm{~cm}$ below the lower border of the crural diaphragm at inspiration (referenced to atmospheric pressure), TP was defined as the pressure $5 \mathrm{~cm}$ above the upper border of the LES at inspiration (referenced to atmospheric pressure), and TAPG was calculated as AP minus TP. LESP, referenced to the pressure at the same level of AP measurement $(1 \mathrm{~cm}$ below the lower border of the crus) was also assessed, and adjusted TAPG was calculated as TAPG minus pressure at the same level of AP measurement. Presumably, gastroesophageal reflux can be induced if TAPG overcomes LESP, which works as a fundamental barrier to reflux. ${ }^{16,17}$

Manometric esophageal length between the lower border of the upper esophageal sphincter and the upper border of the LES at the end inspiration was assessed (Figure 1). The esophageal length index (ELI), which is the ratio of endoscopic esophageal length (centimeters) to patient height (meters), has been proposed by Yano and colleagues. ${ }^{18}$ We applied this concept to HRM evaluation to calculate the manometric ELI.

\section{4-Hour pH Monitoring}

Pre- and post-LTx ambulatory esophageal $\mathrm{pH}$ monitoring were performed using a catheter-based system (Sandhill Scientific Inc, Highlands Ranch, Colo) or a wireless probe (Bravo; Medtronic, Minneapolis, Minn) within 1 week before or after HRM study. The catheter-based $\mathrm{pH}$ probe was passed transnasally and positioned $5 \mathrm{~cm}$ above the upper border of the manometrically defined LES. The capsule was passed transorally and 


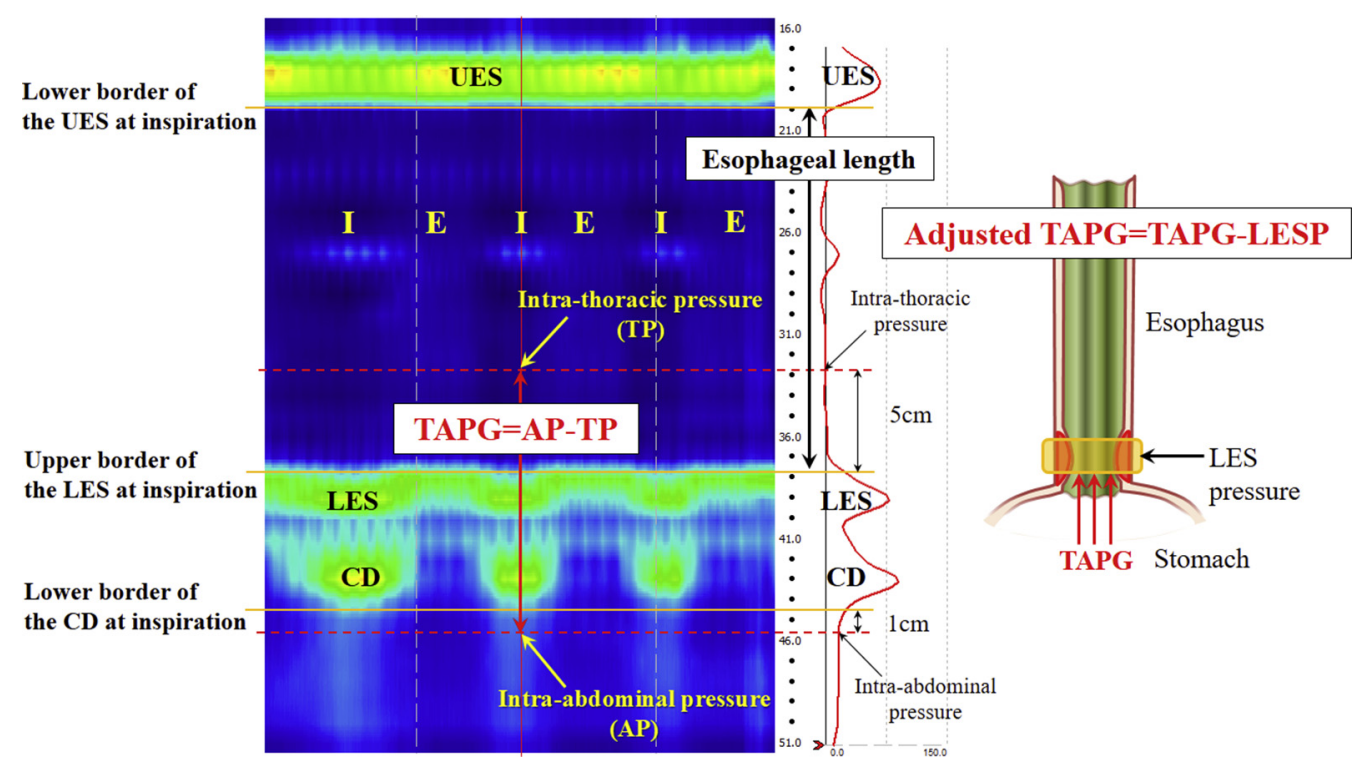

FIGURE 1. TAPG and esophageal length. In the resting period without swallowing, coughing, or secondary esophageal peristalsis, TAPG is calculated as AP minus TP at the point of end-inspiration. Adjusted TAPG is calculated as TAPG minus LESP. Esophageal length between the lower border of the upper esophageal sphincter and the upper border of the LES at the same time point. UES, Upper esophageal sphincter; $I$, inspiration; $E$, expiration; TAPG, thoracoabdominal pressure gradient; $L E S P$, resting lower esophageal sphincter pressure; $T P$, intrathoracic pressure; $A P$, intra-abdominal pressure; $L E S$, lower esophageal sphincter; $C D$, crural diaphragm.

positioned $6 \mathrm{~cm}$ above the EGJ under endoscopic guidance. For the capsule-based system, the DeMeester score was calculated as the mean of scores gathered over 2 days. A DeMeester score greater than 14.72 signified pathological reflux. All studies were reviewed by a single author (TM). Tests were deemed to be of poor quality if a study was recorded for less than 18 hours.

\section{Esophagogastroduodenoscopy and Gastric Emptying Study}

Pre- and post-LTx esophagogastroduodenoscopy (EGD) were performed by thoracic surgeons. Most patients underwent EGD within 6 months pre- and post-LTx. Pre- and post-LTx gastric emptying studies were performed within 6 months before and after LTx. Delayed gastric emptying was defined according to the proposed diagnostic criteria. ${ }^{19}$

\section{Statistical Analysis}

All statistical analyses were performed using SPSS version 22.0.0.0 (IBM SPSS Statistics; Armonk, NY). Differences in categoric variables between patients with obstructive and patients with restrictive lung disease were assessed using the chi-square or Fisher exact test. The MannWhitney $U$ test was used to compare continuous variables between the groups. McNemar's test was used to compare categoric variables between pre- and post-LTx outcomes in each individual, and continuous variables in each individual were compared by Wilcoxon signed-rank test. Continuous variables are expressed as median with interquartile range.

\section{RESULTS}

A total of 204 patients underwent LTx at our institution (Norton Thoracic Institute, Phoenix, Ariz) during the study period. Of these patients, 142 underwent complete pre- and post-LTx HRM with a 24-hour $\mathrm{pH}$ study. Some patients were urgently evaluated for transplant and therefore did not undergo complete preoperative foregut evaluation. $\mathrm{Pa}$ tients who had undergone previous LTx $(\mathrm{n}=8)$, who had undergone prior foregut surgery or endoscopic esophageal intervention $(\mathrm{n}=7)$, or who had either studies unavailable for reanalysis or studies of poor quality $(n=15)$ were excluded. The remaining 112 patients were included for initial analysis. All patients underwent bilateral LTx. The mean age was 62.2 years at the LTx date, 62 patients $(55.4 \%)$ were men, and the mean body mass index (BMI) was $25.8 \mathrm{~kg} / \mathrm{m}^{2}$. Preoperative and postoperative HRM studies with $\mathrm{pH}$ monitoring were performed at an average of 4.1 and 4.9 months before and after LTx, respectively. A total of 51 patients $(45.5 \%)$ were diagnosed with obstructive lung disease, 56 patients $(50.0 \%)$ were diagnosed with restrictive lung disease, 3 patients $(2.7 \%)$ were diagnosed with pulmonary hypertension, and 2 patients $(1.8 \%)$ were diagnosed with cystic fibrosis. Of these patients, 5 diagnosed with pulmonary hypertension or cystic fibrosis were excluded from further statistical evaluation. We then assessed patients with obstructive and restrictive lung disease.

\section{pH Study Before and After Lung Transplantation}

Of the 107 patients diagnosed with obstructive or restrictive lung disease, an abnormal DeMeester score (ie, $>14.72)$ was observed in 34 patients $(31.8 \%)$ before LTx and in 38 patients $(35.5 \%)$ after LTx $(P=.563)$. Of note, 16 of 34 patients $(47.1 \%)$ with abnormal pre-LTx DeMeester scores had normal scores post-LTx, whereas 20 of 73 patients $(27.4 \%)$ with normal pre-LTx DeMeester 


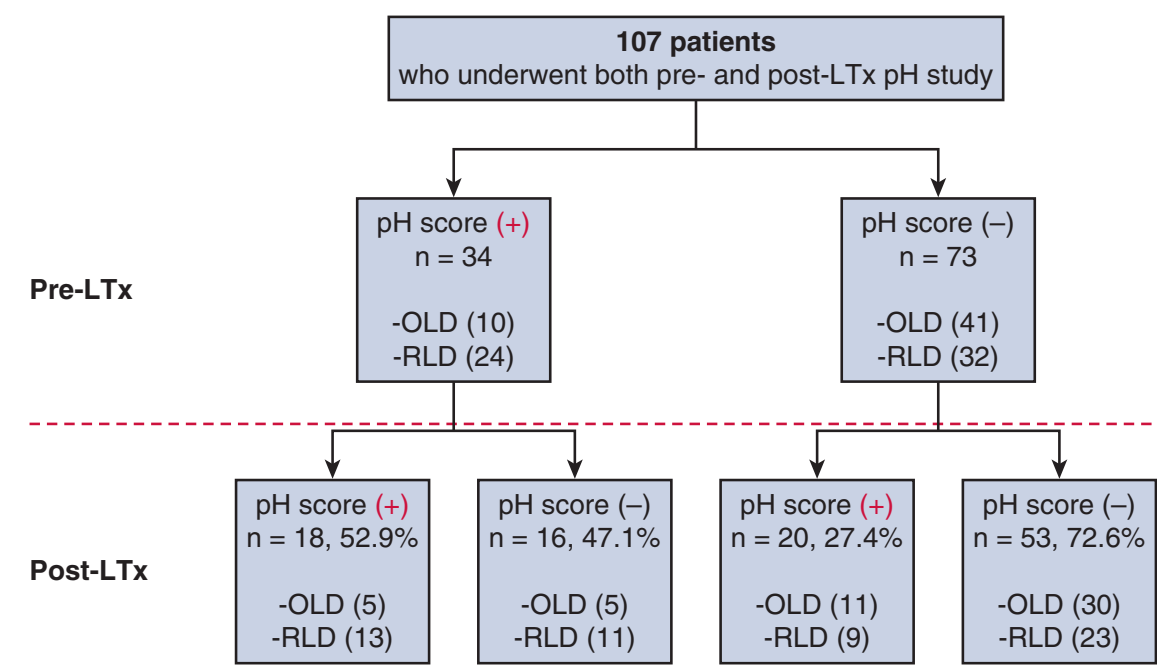

FIGURE 2. Demographic change in patients with GERD pre- and post-LTx based on ambulatory pH monitoring. Half of the patients with an abnormal pH score before LTx $(16 / 34,47.1 \%)$ showed no evidence of pathological reflux after transplantation, whereas one-quarter of patients without pathological reflux $(20 / 73,27.4 \%)$ had an abnormal $\mathrm{pH}$ score post-transplant. $L T x$, Lung transplantation; $O L D$, obstructive lung disease; $R L D$, restrictive lung disease.

scores had abnormal DeMeester scores post-LTx (Figure 2). A similar trend was seen in each subgroup of underlying lung disease. The DeMeester score was significantly increased after LTx in patients with obstructive lung disease; however, in patients with restrictive lung disease, there was no difference in median $\mathrm{pH}$ scores pre- and post-LTx (Figure 3, A).

Figure 4 and Table 1 show the outcomes in the parameters for gastroesophageal reflux on $\mathrm{pH}$ study at the time of preand post-LTx evaluation. At the pre-LTx testing, significant differences were evident between the obstructive and restrictive lung disease cohorts in terms of the prevalence of pathological reflux $(19.6 \%$ vs $42.9 \%, P=.010)$, DeMeester score (4.7 vs 12.1, $P=.003$ ), total acid reflux time $(1.0 \%$ vs $3.1 \%, P=.002)$, number of reflux episodes (21.0 vs 51.5, $P=.002$ ), number of long (ie, $>5$ minutes) reflux episodes ( 0.0 vs $1.2, P=.006$ ), and duration of the longest reflux episode ( 3.9 vs 7.3 minutes, $P=.028$ ). However, after LTx, all of these differences were below the threshold for statistical significance.

\section{High-Resolution Esophageal Manometry Before and After Lung Transplantation}

Esophageal motility. A high prevalence of esophageal motility disorders was noted both pre- and post-LTx (preLTx: 55.1\% [59/107 patients]; post-LTx: 45.8\% [49/107 patients]). A total of 55 of 107 patients $(51.4 \%$ ) had a change in manometric diagnosis based on the Chicago Classification $\mathrm{v} 3.0^{13}$ from pre-LTx to post-LTx that indicated increased peristaltic vigor (DCI: 1016.9 vs $1515.8 \mathrm{~mm} \mathrm{Hg} \cdot \mathrm{s} \cdot \mathrm{cm}, P<.001)$. Patients with restrictive lung disease had lower peristaltic vigor than patients with obstructive lung disease both before and after LTx
(Table 1). Figure 3, $B$, shows that both cohorts had more vigorous DCI after LTx. The improved manometric profile was more obvious in patients with restrictive lung disease (esophageal dysmotility pre-LTx: $60.7 \%$ vs post-LTx: $39.3 \%, P=.023$; Table 1 ).

Lower esophageal sphincter parameters. A total of 30 of 107 patients $(28.0 \%)$ had manometric hiatal hernia preLTx, and 17 patients $(15.9 \%)$ had hiatal hernia post-LTx $(P=.032)$. Parameters for LES antireflux function, such as LESPI and AL, were significantly improved after LTx (222.6 vs $260.6 \mathrm{~mm} \mathrm{Hg} \cdot \mathrm{s} \cdot \mathrm{cm}, P=.024 ; 2.2$ vs $2.3 \mathrm{~cm}$, $P=.035$, respectively). This improvement was more profound in the obstructive lung disease cohort (Table 1).

Esophageal length. Manometric ELI (ie, esophageal length [centimeters] divided by patient height [meters]) was also assessed. Before LTx, patients with obstructive lung disease had significantly longer esophageal length and higher ELI than patients with restrictive lung disease ( 24.5 vs $22.0 \mathrm{~cm}, P<.001 ; 14.4$ vs $12.9, P<.001$, respectively); however, after LTx, no differences were seen in these parameters between the 2 groups (Table 1). In the obstructive lung disease group, esophageal length and ELI were significantly decreased after transplantation in each individual, whereas in the restrictive lung disease cohort, they were significantly increased post-LTx (Figure 3, C, and Table 1).

Thoracoabdominal pressure gradient. Table 1 shows that the AP was similar between the obstructive and restrictive lung disease groups both pre- and post-LTx (13.6 vs $15.2 \mathrm{~mm} \mathrm{Hg}, P=.388 ; 15.3$ vs $17.6 \mathrm{~mm} \mathrm{Hg}, P=.346$, respectively), although preoperative BMI was significantly lower in patients with obstructive lung disease than in those with restrictive lung disease (24.2 vs $27.2 \mathrm{~kg} / \mathrm{m}^{2}, P=.007$ ). 


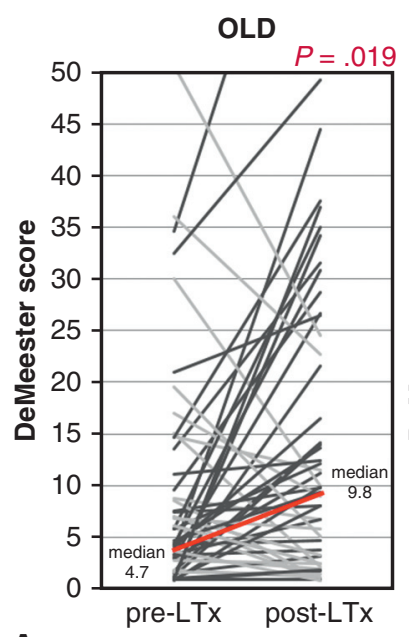

A

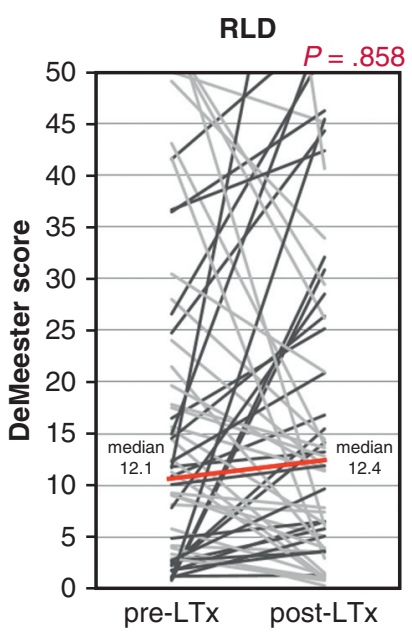

RLD
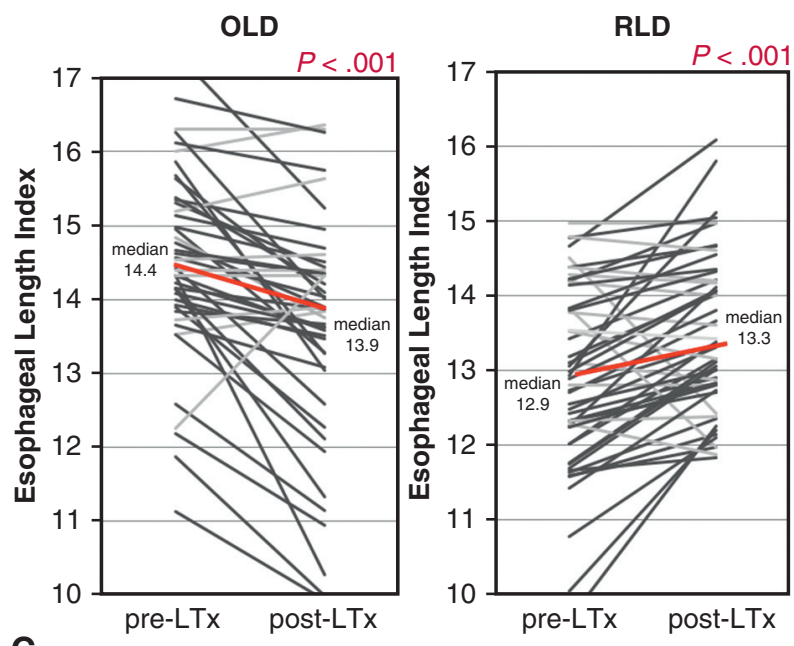

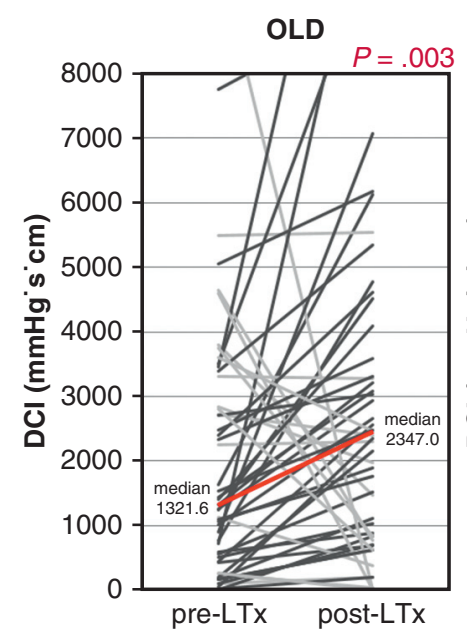

B
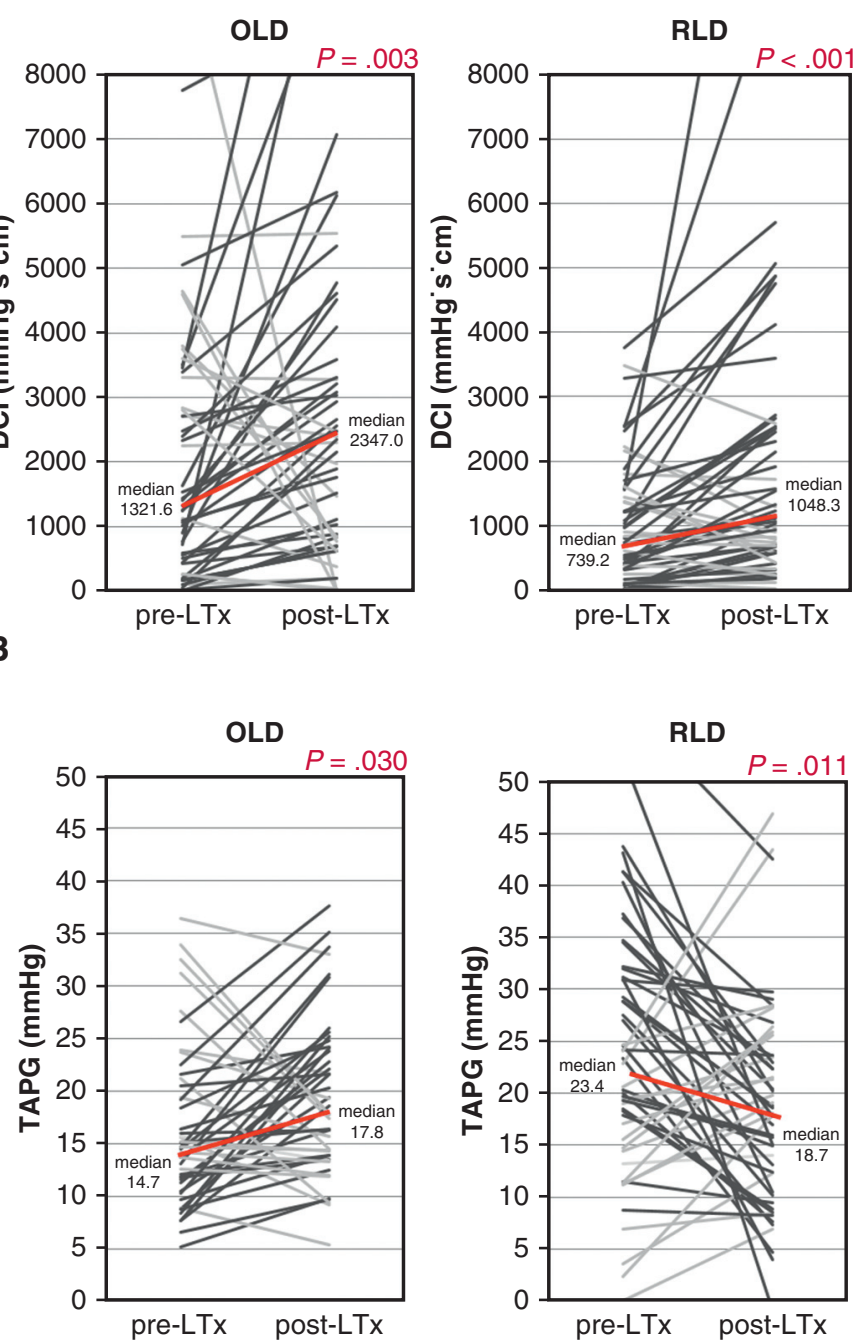

FIGURE 3. Differences in foregut function tests from pre- to post-LTx in each underlying lung disease. A, Change in DeMeester score from pre- to postLTx. B, Change in DCI from pre- to post-LTx. C, Change in ELI from pre- to post-LTx. D, Change in TAPG from pre- to post-LTx. OLD, Obstructive lung disease; $L T x$, lung transplant; $R L D$, restrictive lung disease; $D C I$, distal contractile integral; $T A P G$, thoracoabdominal pressure gradient.

Pretransplant, the restrictive lung disease group had lower TP, greater TAPG, and elevated adjusted TAPG than the obstructive lung disease group $(-6.9$ vs $-0.8 \mathrm{~mm} \mathrm{Hg}$, $P<.001 ; 23.4$ vs $14.7 \mathrm{~mm} \mathrm{Hg}, P<.001 ; 0.7$ vs $-10.3 \mathrm{~mm} \mathrm{Hg}, P=.001)$. However, no differences were seen in TP, TAPG, or adjusted TAPG post-LTx. Figure 3, $D$, shows that TAPG was significantly increased in each patient with obstructive lung disease after LTx compared with before LTx (17.8 vs $14.7 \mathrm{~mm} \mathrm{Hg}, P=.030$ ), whereas TAPG in the restrictive lung disease cohort was lower post-LTx than pre-LTx (18.7 vs $23.4 \mathrm{~mm} \mathrm{Hg}, P=.011$ ).

\section{Gastric Emptying Study Before and After Lung Transplantation}

Of the 107 patients with obstructive and restrictive pulmonary disease, gastric emptying studies were performed in 86 patients pre-LTx and in 95 patients post-LTx, at an average of 4.7 months before and 4.4 months after transplantation, respectively. The prevalence of delayed gastric emptying was significantly increased post-LTx compared with pre-LTx $(21.1 \%$ vs $2.3 \%, P<.001)$. Patients in both groups had similar prevalence of delayed gastric emptying both pre- and post-LTx (Table 1). After LTx, 9 of 20 patients $(45.0 \%)$ with delayed gastric emptying had an abnormal DeMeester score.

\section{Post-Transplant Foregut Intervention}

Manometric criteria of achalasia were satisfied in 2 patients pre-LTx and 4 patients post-LTx. However, none of these patients had clinical evidence of poor esophageal clearance or EGJ outflow obstruction based on objective evaluation that included EGD and videofluoroscopy. 

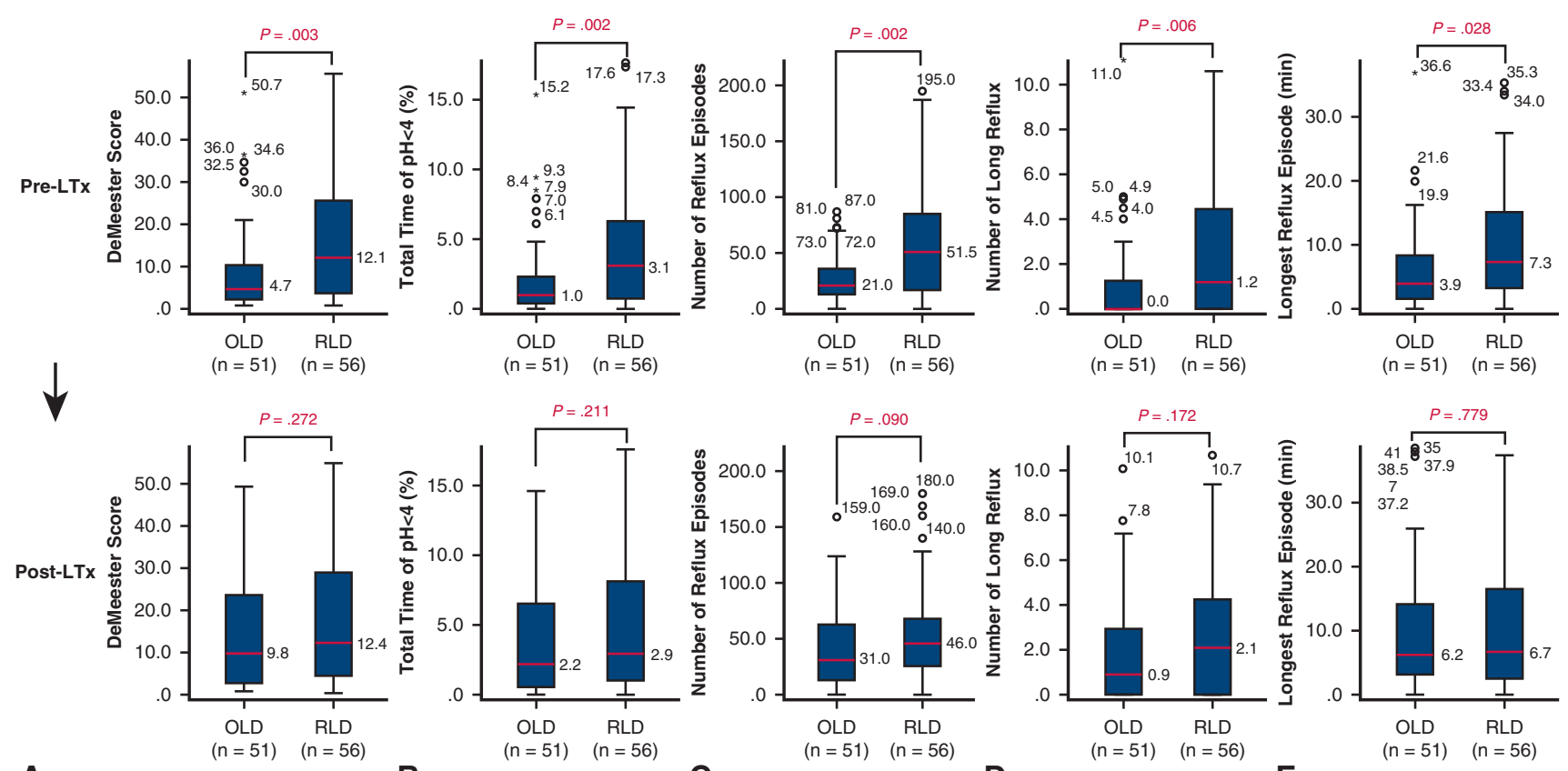

FI

B

C

D

E

FIGURE 4. Differences in parameters for $\mathrm{pH}$ monitoring between the obstructive and restrictive lung disease groups pre- and post-LTx. A, DeMeester scores. B, Total time pH less than 4. C, Number of reflux episodes. D, Number of long-reflux periods. E, Longest reflux episode. More severe acid exposure on the distal esophagus was seen in the obstructive lung disease cohort than in the restrictive lung disease cohort before LTx. The differences in all $\mathrm{pH}$ parameters between the 2 cohorts were diminished after LTx. In the box and whisker plots, 51 patients with obstructive lung disease and 56 patients with restrictive lung disease were included (no missing data). The ends of the box represent the upper and lower quartiles; the middle horizontal line inside the box represents the median; the upper and lower whiskers represent the maximum and minimum values of nonoutliers; and extra dots represent outliers. $L T x$, Lung transplant; $O L D$, obstructive lung disease; $R L D$, restrictive lung disease.

Therefore, we did not perform foregut intervention (eg, balloon dilation or myotomy) in these patients pre- or post-LTx. On the other hand, GERD based on post-LTx foregut testing was addressed with laparoscopic Toupet fundoplication in 1 patient who had abnormal $\mathrm{pH}$ study results after LTx.

\section{DISCUSSION}

This study has revealed significant changes in foregut function from the pretransplant period to the posttransplant period. Esophageal body motility (ie, DCI) and EGJ antireflux function (ie, presence of hiatal hernia, LESP, LESPI, and AL) were significantly improved after LTx, indicating that the competency of the antireflux complex was reinforced post-LTx, based on HRM evaluation. However, the prevalence of delayed gastric emptying was obviously increased, probably because of intraoperative vagal nerve damage and the effects of immunosuppressive medications, which likely contributed to an increased risk of gastroesophageal reflux. Overall, the prevalence of pathological reflux did not change pre- and post-LTx in this study population $(31.8 \%$ vs $35.5 \%, P=.563)$.

In 2003, Young and colleagues ${ }^{1}$ first reported an increased prevalence of GERD post-LTx compared with
pre-LTx in 23 patients. Using ambulatory $\mathrm{pH}$ monitoring, they showed that 8 of 23 patients $(34.8 \%)$ had abnormal distal esophageal acid exposure before transplant, and 15 of 23 patients $(65.2 \%)$ had pathological reflux after LTx. However, their study population was mostly composed of patients with a pre-LTx diagnosis of chronic obstructive pulmonary disease (COPD) representing obstructive lung disease; 12 of 23 patients (52\%) had COPD, and the restrictive pulmonary disease group comprised just 3 patients, who were diagnosed with idiopathic pulmonary fibrosis (IPF).

In 2005, D'Ovidio and colleagues ${ }^{2}$ assessed $\mathrm{pH}$ studies in a total of 78 LTx candidates and demonstrated a lower prevalence of abnormal DeMeester scores in patients with COPD than in patients with IPF (19\% vs $32 \%)$. In 2006, Sweet and colleagues ${ }^{3}$ confirmed that finding with an even higher prevalence $(43 \%$ vs $73 \%)$. Our results of pre-LTx pH monitoring correspond with the abnormal DeMeester rates reported by these previous studies. In the present study, patients in the obstructive lung disease group had a significantly lower prevalence of pre-LTx abnormal DeMeester scores than patients in the restrictive lung disease cohort (19.6\% vs $42.9 \%, P=.010)$, in agreement with the differences in all other $\mathrm{pH}$ parameters with statistical 
TABLE 1. Patient characteristics

\begin{tabular}{|c|c|c|c|c|c|c|}
\hline \multirow[b]{3}{*}{ Variable } & \multicolumn{3}{|c|}{ Pre-LTx } & \multicolumn{3}{|c|}{ Post-LTx } \\
\hline & \multicolumn{4}{|c|}{ OLD vs RLD } & \multicolumn{2}{|r|}{ OLD vs RLD } \\
\hline & $\operatorname{OLD}(\mathbf{n}=\mathbf{5 1})$ & $\operatorname{RLD}(\mathbf{n}=56)$ & $P$ value & OLD $(\mathbf{n}=\mathbf{5 1})$ & $\operatorname{RLD}(\mathbf{n}=56)$ & $P$ value \\
\hline Age, $y^{*}$ & $63.0(57.0-68.0)$ & $66.0(61.0-68.5)$ & .078 & $63.0(57.0-68.0)$ & $66.0(62.0-69.5)$ & .096 \\
\hline $\operatorname{Sex}(M: F)$ & $25: 26$ & $37: 19$ & .082 & $25: 26$ & $37: 19$ & .082 \\
\hline BMI, $\mathrm{kg} / \mathrm{m}^{2 *}$ & $24.2(20.8-27.3)$ & $27.2(24.0-30.5)$ & .007 & $24.7(22.3-28.5)$ & $25.2(23.4-27.7) \dagger$ & .361 \\
\hline \multicolumn{7}{|l|}{$\mathrm{pH}$ monitoring } \\
\hline DeMeester score* & $4.7(1.8-11.1)$ & $12.1(3.7-25.7)$ & .003 & $9.8(2.4-24.5) \ddagger$ & $12.4(4.6-29.0)$ & .272 \\
\hline Abnormal DeMeester score $\S$ & $10(19.6 \%)$ & $24(42.9 \%)$ & .010 & $16(31.4 \%)$ & $22(39.3 \%)$ & .393 \\
\hline$\%$ time $\mathrm{pH}<4, \% *$ & $1.0(0.3-2.3)$ & $3.1(0.8-6.3)$ & .002 & $2.2(0.4-6.6) \dagger$ & $2.9(1.0-8.1)$ & .211 \\
\hline No. of reflux episodes* & $21.0(13.0-36.0)$ & $51.5(17.0-85.0)$ & .002 & $31.0(13.0-63.0)$ & $46.0(25.5-68.0)$ & .090 \\
\hline No. of long reflux episodes* & $0.0(0.0-1.3)$ & $1.2(0.0-4.5)$ & .006 & $0.9(0.0-3.1) \ddagger$ & $2.1(0.0-4.3)$ & .172 \\
\hline Longest reflux episode, min* & $3.9(1.4-8.6)$ & $7.3(3.3-15.1)$ & .028 & $6.2(3.0-14.2)$ & $6.7(2.5-16.5)$ & .779 \\
\hline \multicolumn{7}{|l|}{ HRM findings } \\
\hline Manometric hiatal hernia $\S$ & $16(31.4 \%)$ & $14(25.0 \%)$ & .464 & $9(17.6 \%)$ & $8(14.3 \%)$ & .839 \\
\hline LESP, $\mathrm{mm} \mathrm{Hg} *$ & $31.2(20.2-38.9)$ & $32.4(17.9-37.3)$ & .808 & $32.3(21.5-52.2) \ddagger$ & $32.0(20.6-39.8)$ & .293 \\
\hline LESPI, $\mathrm{mm} \mathrm{Hg} \cdot \mathrm{s} \cdot \mathrm{cm}^{*}$ & $196.5(89.5-490.2)$ & $236.3(112.5-338.9)$ & .953 & $262.5(130.4-699.2) \ddagger$ & $256.0(93.2-507.2)$ & .317 \\
\hline $\mathrm{OL}, \mathrm{cm}^{*}$ & $2.7(2.3-3.1)$ & $2.8(2.4-3.3)$ & .465 & $2.7(2.2-3.3)$ & $2.8(2.5-3.2)$ & .955 \\
\hline $\mathrm{AL}, \mathrm{cm}^{*}$ & $2.1(1.2-2.5)$ & $2.2(1.8-2.7)$ & .455 & $2.3(1.8-2.7) \ddagger$ & $2.4(2.0-2.8)$ & .683 \\
\hline \multicolumn{7}{|l|}{ HRM diagnosis $\S$} \\
\hline Normal & $26(51.0 \%)$ & $22(39.3 \%)$ & .224 & $24(47.1 \%)$ & $34(60.7 \%) \ddagger$ & .157 \\
\hline IEM & $14(27.5 \%)$ & $21(37.5 \%)$ & .307 & $8(15.7 \%)$ & $11(19.6 \%) \ddagger$ & .593 \\
\hline Fragmented peristalsis & $1(2.0 \%)$ & $3(5.4 \%)$ & .345 & $2(3.9 \%)$ & $1(1.8 \%)$ & .465 \\
\hline DES & $1(2.0 \%)$ & 0 & .477 & 0 & 0 & N/A \\
\hline Jackhammer esophagus & $3(5.9 \%)$ & 0 & .105 & $6(11.8 \%)$ & $1(1.8 \%)$ & .043 \\
\hline Absent contractility & 0 & $5(8.9 \%)$ & .036 & 0 & $2(3.6 \%)$ & .272 \\
\hline EGJOO & $5(9.8 \%)$ & $4(7.1 \%)$ & .440 & $7(13.7 \%)$ & $7(12.5 \%)$ & .851 \\
\hline Achalasia & $1(2.0 \%)$ & $1(1.8 \%)$ & .728 & $4(7.8 \%)$ & 0 & .048 \\
\hline Mean DCI, $\mathrm{mm} \mathrm{Hg} \cdot \mathrm{s} \cdot \mathrm{cm}^{*}$ & $\begin{array}{l}1321.6 \\
\quad(447.4-3305.0)\end{array}$ & $\begin{array}{l}739.2 \\
\quad(201.7-1492.6)\end{array}$ & .005 & $\begin{array}{l}2347.0 \\
\quad(772.5-4089.3) \dagger\end{array}$ & $\begin{array}{l}1048.3 \\
\quad(50.3 .5-2519.7) \|\end{array}$ & .023 \\
\hline $\mathrm{TP}, \mathrm{mm} \mathrm{Hg} *$ & $-0.8(-4.5$ to 1.2$)$ & $-6.9(-14.4$ to -1.0$)$ & $<.001$ & $-3.1(-5.8$ to 0.7$)$ & $-2.1(-4.8$ to 0.9$) \|$ & .376 \\
\hline $\mathrm{AP}, \mathrm{mm} \mathrm{Hg} *$ & $13.6(10.8-17.8)$ & $15.2(11.2-20.1)$ & .388 & $15.3(12.7-20.5)$ & $17.6(13.6-21.7)$ & .346 \\
\hline TAPG, mm Hg* & $14.7(11.3-20.5)$ & $23.4(15.5-32.0)$ & $<.001$ & $17.8(13.9-24.2) \ddagger$ & $18.7(10.7-25.3) \ddagger$ & .699 \\
\hline Adjusted TAPG, mm Hg* & $-10.3(-20.7$ to -1.8$)$ & $0.7(-13.1$ to 9.9$)$ & .001 & $-8.1(-26.4$ to 0.6$)$ & $-6.2(-22.2$ to 3.1$) \ddagger$ & .414 \\
\hline Esophageal length, $\mathrm{cm}^{*}$ & $24.5(23.1-25.6)$ & $22.0(20.3-23.8)$ & $<.001$ & $23.4(21.8-24.3) \|$ & $22.5(21.3-24.5) \|$ & .471 \\
\hline Manometric ELI* & $14.4(13.9-15.3)$ & $12.9(12.0-13.8)$ & $<.001$ & $13.9(13.2-14.4) \|$ & $13.3(12.6-14.2) \|$ & .151 \\
\hline Gastric emptying study & $\mathrm{n}=43$ & $\mathrm{n}=43$ & & $\mathrm{n}=47$ & $\mathrm{n}=48$ & \\
\hline Delayed gastric emptying $\S$ & $1(2.3 \%)$ & $1(2.3 \%)$ & .747 & $10(21.3 \%) \dagger$ & $10(20.8 \%)$ & 958 \\
\hline
\end{tabular}

Values in bold are statistically significant. $L T x$, Lung transplantation; $O L D$, obstructive lung disease; $R L D$, restrictive lung disease; $B M I$, body mass index; $H R M$, high-resolution manometry; $L E S P$, resting lower esophageal sphincter pressure; $L E S P I$, lower esophageal sphincter pressure integral; $O L$, overall lower esophageal sphincter length; $A L$, abdominal LES length; IEM, ineffective esophageal motility; DES, diffuse esophageal spasm; $N / A$, not available; $E G J O O$, esophagogastric junction outflow obstruction; $D C I$, distal contractile integral; $T P$, intrathoracic pressure; $A P$, intra-abdominal pressure; $T A P G$, thoracoabdominal pressure gradient; $E L I$, esophageal length index. *Values expressed as median (interquartile range). $\dagger P<.01 . \ddagger P<.05$. $\S$ Values expressed as number (\%). $\| P<.001$ compared with pre-LTx in each individual.

significance (Figure 4). However, all of these differences between the 2 cohorts disappeared after LTx. This is direct evidence for a disease-specific mechanism in lung disease that facilitates gastroesophageal reflux.

Obstructive lung disease and restrictive lung disease have opposing pulmonary mechanics. Forced expiration and larger lung volumes are observed in patients with obstructive pulmonary disease, whereas forced inspiration and smaller lung volume are observed in patients with restrictive pulmonary disease. Forced inspiration makes TP more negative, resulting in higher TAPG and adjusted TAPG. Also, elevated BMI is known to be associated with the pathogenesis of GERD, secondary to increased AP, which is a component of TAPG. In the present study, the restrictive lung disease group had significantly higher BMI than the obstructive lung disease group before LTx. Recently, we demonstrated that the adjusted TAPG correlates with pathological reflux in LTx candidates. ${ }^{16}$ In the present study, adjusted TAPG was higher in the restrictive lung disease group than in the obstructive lung disease 
group before LTx; however, parameters for EGJ antireflux functions (eg, hiatal hernia, LESP, LESPI, OL, and AL) were similar between the groups, suggesting that adjusted TAPG may be the primary factor responsible for differences noted in the $\mathrm{pH}$ studies. The difference in adjusted TAPG was diminished after LTx, as would be expected if this paradigm were true.

Higher manometric ELI (ie, esophageal length divided by patient height) in the obstructive lung disease cohort and lower ELI in the restrictive lung disease cohort were also seen before LTx (14.4 vs $12.9, P<.001)$. This can be explained by diaphragmatic excursions due to the changes of lung volume depending on underlying pulmonary disease. Figure 5 depicts typical HRM findings in patients with obstructive and restrictive lung disease. In patients with obstructive lung disease, lung size is increased, which pushes the diaphragm down caudally, and stretches the mediastinum and esophagus vertically. On the other hand, in patients with restrictive lung disease, the lung size is decreased, which pulls the diaphragm up cephalad. This volume reduction simultaneously stretches the esophagus horizontally.

The esophagus has both longitudinal and circular muscle layers. The pressure sensors on the HRM catheter can only detect force in the horizontal direction. The explanation for impaired esophageal body contraction in patients with restrictive lung disease can be intuitively understood if the horizontal esophageal extension is a burden on the circular muscle contraction. In patients with obstructive lung disease, on the other hand, contraction of the longitudinal muscle may be impaired as the result of vertical esophageal extension. Swallow-induced longitudinal esophageal
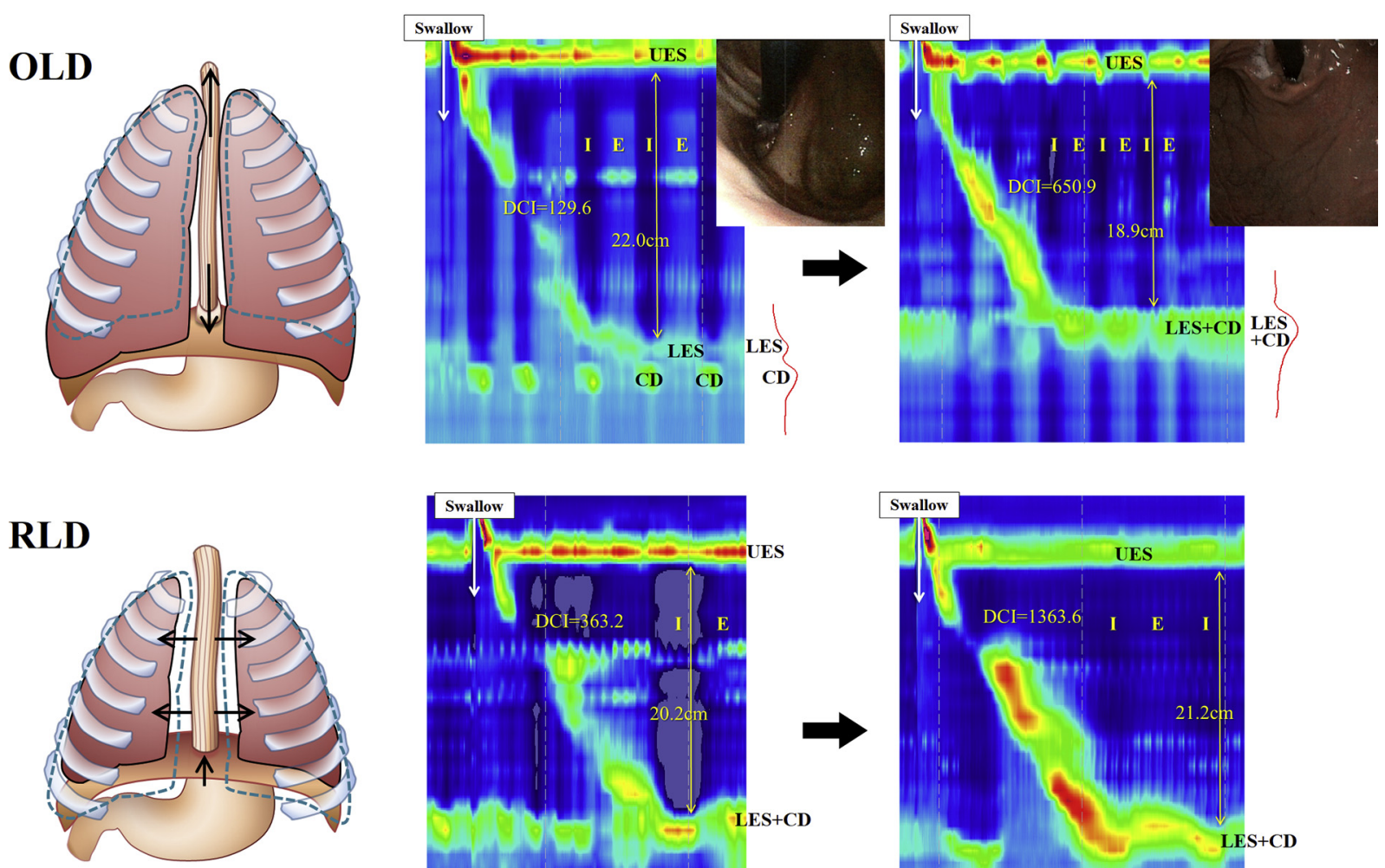

Pre-LTx

\section{Post-LTx}
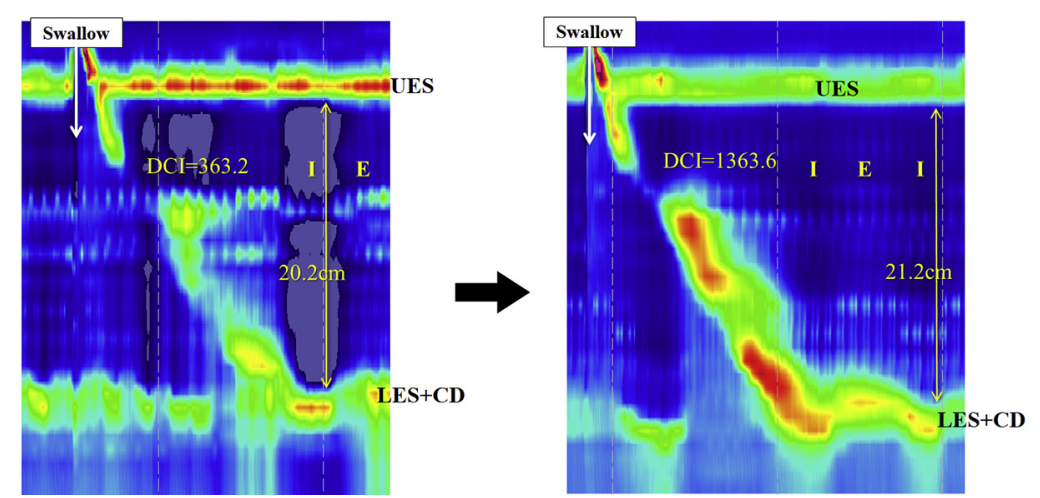

FIGURE 5. Advanced lung disease significantly changes lung volume, resulting in esophageal extension either vertically or horizontally. This phenomenon can impair esophageal motility in patients with obstructive lung disease and in patients with restrictive lung disease. A, In patients with obstructive lung disease, the diaphragm is pushed down by the enlarged lung, so longer esophageal length, small hiatal hernia, and impaired esophageal contractile vigor are seen before LTx. A shorter esophageal length, intact EGJ morphology, and normal peristaltic vigor are noted in the same patient after LTx. The change in the presence of hiatal hernia can be endoscopically confirmed. B, In patients with restrictive lung disease, the diaphragm is pulled up by the lung reduced in size, and the esophagus is simultaneously stretched horizontally. A shorter esophageal length, more negative TP (dark blue color), and impaired esophageal contractile vigor are seen before LTx. Longer esophagus, higher TP, and intact peristaltic vigor are observed after LTx. LTx, Lung transplantation; $O L D$, obstructive lung disease; $R L D$, restrictive lung disease; $U E S$, upper esophageal sphincter; $I$, inspiration; $E$, expiration; $D C I$, distal contractile integral; $L E S$, lower esophageal sphincter; $C D$, crural diaphragm. 
muscle contraction results in transient axial esophageal shortening, which increases the longitudinal density of the circular muscle fibers, providing greater horizontal force by increased muscle fibers per unit area. ${ }^{20-22}$ Thus, impaired longitudinal muscle contraction secondary to vertical esophageal extension contributes to decreasing horizontal esophageal contractile amplitude.

This theory can offer insight into changes in foregut function after LTx in patients with obstructive lung disease or restrictive lung disease. Both obstructive and restrictive lung disease cohorts showed significantly increasing esophageal peristaltic vigor after LTx because impairment in esophageal body contraction was reduced. In addition, LES barrier function was significantly improved after LTx, potentially because of anatomic and physiologic changes in the mediastinum, including the diaphragmatic location and the esophageal lengthening. Some patients had an elevated LES relaxation pressure resulting in a diagnosis of achalasia based on Chicago classification v3.0 $0^{13}$; however, they showed no objective evidence of poor esophageal clearance and therefore required no foregut intervention.

Because GERD is a multifactorial disease, we could find no significant predictor for post-LTx pathological reflux before transplantation in each individual, although some explanation for changes in $\mathrm{pH}$ studies can be added after transplantation. The present study showed that approximately half of patients with GERD pre-LTx had no evidence of GERD post-LTx, whereas one-quarter of patients without objective evidence of GERD pre-LTx developed GERD post-LTx (Figure 2). If patients are to be considered for fundoplication, we suggest that this procedure be recommended after LTx whenever clinically possible and after further foregut function studies.

It has been reported that restrictive lung disease may have concomitant primary esophageal hypomotility. ${ }^{11,12}$ The present study demonstrates that some patients with aperistalsis who undergo bilateral LTx for restrictive lung disease (predominantly for IPF) show improved esophageal motility postoperatively, which may make them eligible for antireflux surgery (ie, fundoplication) if pathological reflux is noted on postoperative studies. This would allow these patients to receive LTx, even though some centers exclude these patients from LTx consideration. However, we must be cautious in expecting all patients to show improvement, and we are currently examining this cohort of patients to identify those who are more likely to show improvement in esophageal motility after transplant (Video 1).

A multidisciplinary approach to assessing esophageal function is key in decision making, and should be undertaken before and after LTx. Preoperative foregut function testing is still valuable, because it allows the diagnosis of other esophageal motility disorders (eg, achalasia) and

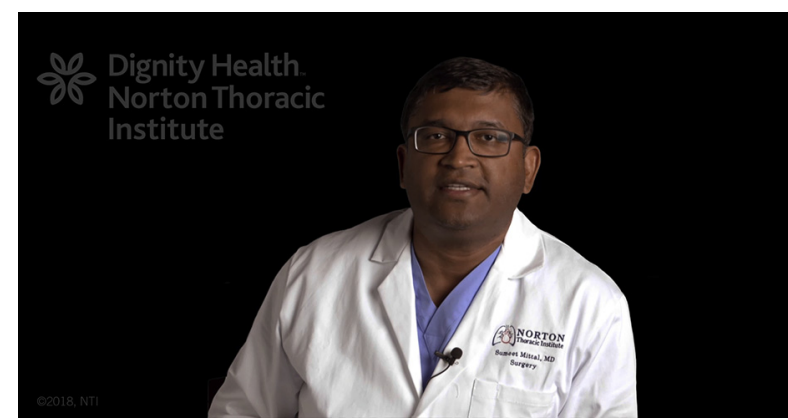

VIDEO 1. Senior author Sumeet K. Mittal discusses the importance of this study as it pertains to current clinical strategies for patients with GERD or esophageal hypomotility who undergo LTx. Video available at: https:// www.jtcvs.org/article/S0022-5223(19)30795-0/fulltext.

can provide a diagnosis of sequelae of GERD such as Barrett's esophagus, perhaps with dysplasia, with obvious implications on transplant candidacy. We recommend that all patients undergo post-transplant esophageal function testing within 3 to 6 months as recovery allows, with emphasis on earlier testing for those with preoperative pathologic reflux.

\section{Study Limitations}

This study has certain limitations. Approximately 30\% of patients who underwent LTx during the study period were excluded because of incomplete foregut function tests. The reasons for lack of foregut testing included situations such as emergency LTx or persistence of a critical condition after LTx. This may result in a potential selection bias in patients' clinical characteristics; however, we believe that this study is representative of standard changes in foregut function after LTx. Although it is a retrospective review of patient data, all data were collected prospectively and all HRM was also reanalyzed in a blinded fashion. A healthy control group is desirable to better understand the characteristics in patients with obstructive and restrictive lung disease.

\section{CONCLUSIONS}

Patients with restrictive lung disease had a higher preLTx prevalence of GERD, greater TAPG, and shorter esophageal length than patients with obstructive lung disease; however, these differences were diminished after LTx. Before LTx, esophageal motility was worse in the restrictive pulmonary disease cohort than in the obstructive pulmonary disease cohort; however, both groups showed increased esophageal peristaltic vigor after LTx, resulting in different manometric diagnoses post-LTx in half of the patients. The prevalence of delayed gastric emptying was significantly increased post-LTx. These phenomena indicate certain effects of LTx on foregut function, which is 
confounded by the underlying pulmonary conditions of patients with advanced lung disease.

\section{Conflict of Interest Statement}

Authors have nothing to disclose with regard to commercial support.

The authors thank Dr Cedric G. Bremner for his critical review and Clare Sonntag for her expert editorial assistance.

\section{References}

1. Young LR, Hadjiliadis D, Davis RD, Palmer SM. Lung transplantation exacerbates gastroesophageal reflux disease. Chest. 2003;124:1689-93.

2. D’Ovidio F, Singer LG, Hadjiliadis D, Pierre A, Waddell TK, de Perrot M, et al. Prevalence of gastroesophageal reflux in end-stage lung disease candidates for lung transplant. Ann Thorac Surg. 2005;80:1254-60.

3. Sweet MP, Herbella FA, Leard L, Hoopes C, Golden J, Hays S, et al. The prevalence of distal and proximal gastroesophageal reflux in patients awaiting lung transplantation. Ann Surg. 2006;244:491-7.

4. Davis CS, Shankaran V, Kovacs EJ, Gagermeier J, Dilling D, Alex CG, et al. Gastroesophageal reflux disease after lung transplantation: pathophysiology and implications for treatment. Surgery. 2010;148:737-45.

5. Griffin SM, Robertson AG, Bredenoord AJ, Brownlee IA, Stovold R, Brodlie M, et al. Aspiration and allograft injury secondary to gastroesophageal reflux occur in the immediate post-lung transplantation period (prospective clinical trial). Ann Surg. 2013;258:705-12.

6. Davis RD Jr, Lau CL, Eubanks S, Messier RH, Hadjiliadis D, Steele MP, et al. Improved lung allograft function after fundoplication in patients with gastroesophageal reflux disease undergoing lung transplantation. J Thorac Cardiovasc Surg. 2003;125:533-42.

7. Hartwig MG, Appel JZ, Li B, Hsieh CC, Yoon YH, Lin SS, et al. Chronic aspiration of gastric fluid accelerates pulmonary allograft dysfunction in a rat model of lung transplantation. J Thorac Cardiovasc Surg. 2006;131:209-17.

8. Li B, Hartwig MG, Appel JZ, Bush EL, Balsara KR, Holzknecht ZE, et al. Chronic aspiration of gastric fluid induces the development of obliterative bronchiolitis in rat lung transplants. Am J Transplant. 2008;8:1614-21.

9. Tang T, Chang J-C, Xie A, Davis RD, Parker W, Lin SS. Aspiration of gastric fluid in pulmonary allografts: effect of pH. J Surg Res. 2013;181:e31-8.

10. Biswas Roy S, Elnahas S, Serrone R, Haworth C, Olson MT, Kang P, et al. Early fundoplication is associated with slower decline in lung function after lung transplantation in patients with gastroesophageal reflux disease. J Thorac Cardiovasc Surg. 2018;155:2762-27671.e1.

11. Seccombe J, Mirza F, Hachem R, Gyawali CP. Esophageal motor disease and reflux patterns in patients with advanced pulmonary disease undergoing lung transplant evaluation. Neurogastroenterol Motil. 2013;25:657-63.

12. Basseri B, Conklin JL, Pimentel M, Tabrizi R, Phillips EH, Simsir SA, et al. Esophageal motor dysfunction and gastroesophageal reflux are prevalent in lung transplant candidates. Ann Thorac Surg. 2010;90:1630-6.

13. Kahrilas PJ, Bredenoord AJ, Fox M, Gyawali CP, Roman S, Smout AJ, et al. The Chicago Classification of esophageal motility disorders, v3.0. Neurogastroenterol Motil. 2015;27:160-74.

14. Zaninotto G, DeMeester TR, Schwizer W, Johansson KE, Cheng SC. The lower esophageal sphincter in health and disease. Am J Surg. 1988;155:104-11.

15. Hoshino M, Sundaram A, Mittal SK. Role of the lower esophageal sphincter on acid exposure revisited with high-resolution manometry. J Am Coll Surg. 2011; 213:743-50.

16. Masuda T, Mittal SK, Kovacs B, Smith M, Walia R, Huang J, et al. Thoracoabdominal pressure gradient and gastroesophageal reflux: insights from lung transplant candidates. Dis Esophagus. 2018;31.

17. Ayazi S, DeMeester SR, Hsieh CC, Zehetner J, Sharma G, Grant KS, et al. Thoraco-abdominal pressure gradients during the phases of respiration contribute to gastroesophageal reflux disease. Dig Dis Sci. 2011;56:1718-22.

18. Yano F, Stadlhuber RJ, Tsuboi K, Garg N, Filipi CJ, Mittal SK. Preoperative predictability of the short esophagus: endoscopic criteria. Surg Endosc. 2009; 23:1308-12.

19. Abell TL, Camilleri M, Donohoe K, Hasler WL, Lin HC, Maurer AH, et al. Consensus recommendations for gastric emptying scintigraphy: a joint report of the American Neurogastroenterology and Motility Society and the Society of Nuclear Medicine. Am J Gastroenterol. 2008;103:753-63.

20. Dai Q, Korimilli A, Thangada VK, Chung CY, Parkman H, Brasseur J, et al. Muscle shortening along the normal esophagus during swallowing. Dig Dis Sci. 2006; 51:105-9.

21. Pal A, Brasseur JG. The mechanical advantage of local longitudinal shortening on peristaltic transport. J Biomech Eng. 2002;124:94.

22. Nicosia MA, Brasseur JG, Liu JB, Miller LS. Local longitudinal muscle shortening of the human esophagus from high-frequency ultrasonography. Am J Physiol Gastrointest Liver Physiol. 2001;281:G1022-33.

Key Words: gastroesophageal reflux disease, high-resolution manometry, lung transplant, obstructive lung disease, restrictive lung disease

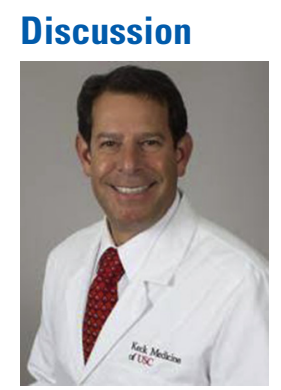

Craig J. Baker. Evaluations for the annual meeting will be conducted through an online survey. This survey will be sent to all meetings' attendees within 1 week of the conclusion of the annual meeting. Once you complete the brief survey, you will be able to retrieve and print out your Continuing Medical Education certificate for your attendance at the annual meeting. The business meeting today is at 12:00 PM, it's for active and senior members only. Immediately after the business meeting is the family luncheon on the ballroom terrace at 12:30 PM. If you have not already signed up for a table for this evening's President's Banquet, you must do so this morning. The seating chart and signup sheets are located at the registration area. All registered attendees must wear their badges to enter the event. As co-moderator of the session, I want to remind the presenting authors that a disclosure slide will be presented for 3 seconds at the beginning of their presentation and please introduce yourself if you have a question after the discussion.

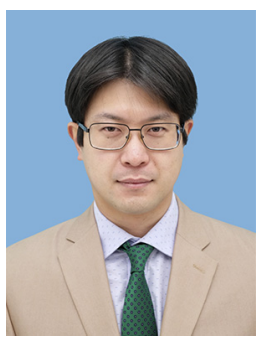

Dr Takahiro Masuda (Phoenix, Ariz). Gastrointestinal dysmotility and GERD are common in patients with advanced lung disease. These are associated with outcomes of LTx. However, the difference in foregut function preand post-LTx remains unstudied. The aim of this study is to evaluate the effect of LTx on foregut function in patients with obstructive and restrictive lung disease.

Patients who underwent LTx at our institution between 2015 and 2016 were included. We excluded patients with poor-quality test results, a history of foregut surgery, or prior LTx. Statistical analysis was performed as shown. 
A total of 204 patients underwent LTx during the study period. Of these, 112 patients met study criteria. Two major groups were those with obstructive and restrictive lung disease. We shall discuss pre- and postchanges in esophageal manometry, 24-hour pH study, and gastric emptying study.

These are the data from manometry. Before LTx, esophageal motility was poor in both obstructive and restrictive lung disease. However, after LTx, a significant improvement in contractive vigor was noted in both groups. ELI was calculated as manometric esophageal lengths divided by height. Before LTx, patients with obstructive lung disease had longer esophageal lengths compared with restrictive lung disease. This is potentially due to changes in resting diaphragmatic position based on underlying pulmonary disease. In obstructive lung disease, the diaphragm is pushed down, whereas in restrictive disease the diaphragm is pulled up. The differences in esophageal lengths between the 2 groups were diminished after LTx. LES parameters associated with antireflux function, including LES pressure, LES pressure integral, and AL, were improved after LTx in patients with obstructive lung disease. This was not noted in restrictive disease. If hiatal hernia size is decreased, LES abdominal lengths are increased and LES is reinforced by abdominal pressure as in obstructive disease, whereas in restrictive lung disease, no anatomic change on EGJ is noted.

We also assessed TAPG across the GE junction. Before LTx, patients with restrictive disease had greater TAPG compared with obstructive disease. This is because forced inspiration in restrictive disease induce more negative TP, resulting in greater TAPG. Presumably, elevated TAPG can facilitate gastroesophageal reflux. After LTx, the difference in TAPG between the 2 cohorts was diminished.

In the 24-hour $\mathrm{pH}$ study, before LTx, restrictive lung disease had significantly more severe acid exposure than obstructive disease. These differences in $\mathrm{pH}$ parameters were completely diminished after LTx. The same trend is seen in TAPG.

These are the data from the gastric emptying studies. The prevalence of delayed gastric emptying was increased in both groups after LTx. This can facilitate gastroesophageal reflux. This is our hypothesis to explain our findings. In obstructive lung disease, lung volume is increased and the diaphragm is pushed down, resulting in hiatal hernia size increase and LES function impairment. The esophagus is stretched vertically. This can impair longitudinal muscle contraction. Lower TAPG resulted in less reflux events. On the other hand, in restrictive lung disease, lung volume is decreased and the diaphragm is pulled up. No anatomic change on the EGJ morphology is noted. The esophagus is stretched horizontally. This can impair circular muscle contraction. Higher TAPG resulted in more severe reflux. All of these changes were diminished after LTx and differences in foregut function between the 2 groups are diminished. Delayed gastric emptying is increased, and this can facilitate gastroesophageal reflux.

Esophageal motility and reflux parameters vary significantly between patients with obstructive and restrictive lung disease. This can be explained by differences in underlying pulmonary dynamics. Restoring pulmonary physiology ameliorates the effects on esophageal motility and reflux. Improvement of esophageal motility is important, especially if patients were not candidates for antireflux surgery because of poor motility pre-LTx.

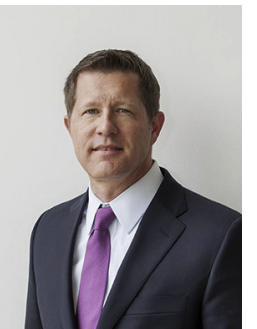

Dr Michael Weyant (Phoenix, Ariz). Dr Masuda, you and your colleagues have performed an immense amount of work in evaluating multiple measures of foregut function pre- and post-LTx. Your series of 142 patients probably represents the largest series of such a topic. It has been known for some time that GERD influences lung function post-LTx, but it has only been recently described that the issue of motility disorders other than achalasia can influence the outcome after LTx, and your findings suggesting that motility can be improved in the majority of patients after LTx should help prevent some patients being excluded for consideration of transplant, so this is important work.

Your description of true motility disorders is somewhat cursory, and given the time, I know that is part of the constraint, but can you elaborate on whether you have patients with true major motility disorders, according to standard classifications, and which patients are you excluding from transplant at this point based on the motility findings beforehand?

Dr Masuda. The question is difficult to answer. From our findings, who will improve in esophageal motility or reflux is not predictable. We are looking at some predictors now, so the question is difficult to answer.

Dr Weyant. Could you just in general describe your algorithm, knowing that you see these changes before and after transplant? Starting with patients before transplant who may have some abnormal motility on manometry studies, how are you managing them before transplant, taking them all the way through post-LTx?

Dr Masuda. First, if patients have poor motility and pathological reflux before LTx, we will place a gastrojejunostomy tube. Then, after LTx, we reassess for motility and $\mathrm{pH}$ studies, and decide to perform fundoplication or not.

Dr Weyant. What type of fundoplication are you choosing to do after transplant?

Dr Masuda. Usually, in our institution, we select Toupet fundoplication.

Dr Weyant. And the reason for that?

Dr Masuda. Toupet fundoplication is better than Nissen fundoplication if the patient has relatively weak peristalsis or some clearance problem. 